\title{
IMPLEMENTATION OF MODERN INTELLIGENT CONTROL METHODS WITHIN THE CONTROL SYSTEMS STUDY MODULE
}

UDC (351.824.1:(004.9:621.317.347):681.5.01)

\section{Marko Milojković, Dragan Antić, Miroslav Milovanović, Darko Mitić}

University of Niš, Faculty of Electronic Engineering,

Department of Control Systems, Niš, Republic of Serbia

\begin{abstract}
This paper presents an innovative project "Implementation of Modern Intelligent Control Methods within the Control Systems Study Module" which is selected to be financed by Serbian Ministry of Education, Science and Technological Development. The project is part of a public call "Development of Higher Education" and it will be realized during a school year 2018/2019. In this paper, the main goals of the project are presented and project activities and expected results are defined. Finally, three courses which are selected to be innovated through the project activities are presented in terms of lecture topics and teaching methods.
\end{abstract}

Key words: industry 4.0, curriculum modernization, artificial intelligence, intelligent control

\section{INTRODUCTION}

The third industrial digital revolution, that took place in the late twentieth century, meant the introduction of computers and automation in the production process. Today, four decades later, we are entering the fourth industrial revolution (Industry 4.0), which is based on the use of information technologies in creating "smart" services and production. In order to respond to new demands in the field of industrial production and to train students in the basic concepts and applications of Industry 4.0, a group of teachers at the Department of Control Systems at the faculty of Electronic Engineering, University of Niš, introduced and innovated several courses related to artificial intelligence and intelligent control.

Received October 17, 2018

Corresponding author: Miroslav B. Milovanović

University of Nis, Faculty of Electronic Engineering, Department of Control Systems, Republic of Serbia

E-mail: miroslav.b.milovanovic@elfak.ni.ac.rs 
The Public call for projects "Development of Higher Education" by the Serbian Ministry of Education, Science and Technological Development was a good opportunity to make a concept of modernization of curriculum for Control Systems study module. In the scope of the proposed project "Implementation of Modern Intelligent Control Methods within the Control Systems Study Module", a plan for innovation of several courses was made: Artificial Intelligence Methods (basic academic studies), Modern Control of Industrial Processes (master academic studies) and Intelligent Control (doctoral academic studies). The emphasis was not only on modernization of lecture topics and teaching methods but also on strengthening the practical aspect of learning as well as developing digital and entrepreneurship competences among the students.

\section{DEVELOPMENT OF Higher EDUCATION IN SERBIA}

The Serbian Ministry of Education, Science and Technological Development called a public competition for projects named "Development of Higher Education". Approved projects are expected to be realized during the 2018/2019 school year and the expenses to be financed are: staff costs, study visits, equipment and software, literature purchasing and books printing. The goal of the Ministry was to finance projects to support higher education institutions in the development of new courses and innovation of existing ones within the framework of accredited study programs, which should contribute to the realization of the following program objectives of the Ministry:

1) to improve the teaching competencies of teachers and teaching process associates;

2) to develop new study programs and to innovate the existing ones that support the labor market needs;

3) to improve the quality of the educational process by creating better conditions for the realization of the teaching process and learning of students;

4) to develop entrepreneurial skills of students and to improve the cooperation between higher-education institutions and companies as well as other stakeholders in local communities;

5) to increase the usage of information technologies in the teaching and learning process;

6) to directly support the realization of the government action plan to improve the IT sector in Serbia.

Projects were ranked according to the following criteria: Project relevance, structure and quality (24\%), Quality of curriculum and teaching (18\%), Development of digital competences (15\%), Developing the entrepreneurial competences (15\%), Human and technical capacities (15\%), Proposed budget (13\%). There were 197 proposed projects, in total, and ministry decided to finance the 65 best ranked ones. Project "Implementation of Modern Intelligent Control Methods within the Control Systems Study Module", proposed by the group of teachers of the Department for Control Systems at the Faculty of Electronic Engineering, University of Niš, was ranked as the $21^{\text {st }}$. 


\section{PROJECT GOALS}

The main goal of the project named "Implementation of Modern Intelligent Control Methods within the Control Systems Study Module" is to innovate the study module of Control Systems through improving the quality of teaching and adapting the curriculum to the needs of the IT industry. The module is very attractive for students, because it enables acquiring knowledge from several scientific fields and represents one of the most perspective IT areas for the future. During the school years, students gain knowledge of computer and information technologies, electronics, automation systems, robotics, measurement, electric power engineering and telecommunications. Practical education and training is provided in the fields of application of microprocessors and microcontrollers, programmable logic controllers, SCADA systems, robots and manipulators, artificial intelligence systems, data acquisition.

Artificial intelligence [1], as one of the main areas of interest for this project, is the future of IT industry and automation. The aim of the project is to innovate a group of courses that deal with the topics of artificial intelligence and their modernization in line with current technologies in this field. Traditional automation and process control techniques are being intensively replaced by new types of intelligent control, so the quality of courses dealing with artificial intelligence is essential for further development of the Control Systems module. Benefits of using intelligent structures are multiple, from energy and resources savings to more efficient and accurate control, prediction of desired parameters, greater system resilience to external disturbances and more reliable work.

\section{PROJECT ACTIVITIES AND EXPECTED RESUltS}

Activities during the realization of the project are planned through three main steps:

1) Analysis of the current state in the scientific fields of interest (analysis of successful related study programs at faculties abroad and study visits, analysis of current labor market requirements, survey of companies on necessary knowledge needed for work).

2) The innovation of the courses (precise definition of knowledge that students need to acquire, designing the contents of the courses - lectures, calculus and laboratory exercises, preparation of the necessary teaching materials, designing of an internet platform for everyday working with students, purchasing and installing laboratory equipment, purchasing the necessary literature).

3) Cooperation with business partners (arranging professional practices for students, identifying the necessary IT competences that a Control Systems engineer should possess after completing studies in the domain of artificial intelligence, consultative help in the development of the curriculum, defining project assignments for students, identifying the topics of lectures that will be held by industry experts to students, designing student ideas to be realized in the university creativity center).

The expected direct results and effects of the project are the following:

- The innovation of the study module Control Systems (innovating three courses) through adapting the curriculum to the needs of the IT industry and the rest of the labor market.

- Innovation of teaching methods with an increased number of practical teaching units.

- Curriculum harmonized with successful related study programs at faculties abroad. 
- Intensified cooperation with colleagues from abroad (through study visits to related departments).

- Realization of new teaching materials for lectures and exercises.

- Improved laboratory equipment.

- Increase in the number of students entering the Control Systems module.

- Increase in the number of professional student practices in successful IT companies.

- Improved creativity and entrepreneurial skills of students.

- Contribution to dual education through cooperation with selected companies and directing students toward start-ups.

- Intensified cooperation with partners from the industry.

\section{HuMAN AND MATERIAL RESOURCES}

The project deals with innovating three courses within the study module Control Systems: Artificial Intelligence Methods (basic academic studies), Modern Control of Industrial Processes (master academic studies) and Intelligent Control (doctoral academic studies). The plan is to introduce new, modern teaching units in the field of artificial intelligence and intelligent control that follow the latest technological innovations in the IT world. The changes will be implemented by a group of teachers with competences in the field of modern information technology, which are reflected in the large number of papers in leading journals dealing with artificial intelligence (neural networks, fuzzy logic, genetic algorithms) [2-4]. Currently, the process of accreditation of study programs at the Faculty of Electronic Engineering is in progress, so all planned innovations of the courses will be announced within the new curriculum of these courses in the new accreditation. In addition to the implementation of new laboratory exercises, it is planned to train students to work in the programming languages Python and $\mathrm{C}++$, as well as in the Matlab software package. Thus, students will learn how to implement programs for control of dynamical systems and design different artificial intelligence systems.

Innovated courses are based on the extensive use of digital teaching technologies. The lectures include a projector, video presentations, an on-line platform for work with students, interactive smartboards and other multimedia content adapted to the fast memorizing of the most important facts inside teaching units. The Department of Control Systems at Faculty of Electronic Engineering, University of Niš has three equipped classrooms within the Laboratory for Modeling, Simulation and Control Systems that will be used for the realization of the courses (http://automatika.elfak.ni.ac.rs/galerija). The first classroom L24 (Fig. 1 and Fig. 2) is equipped with 20 new generation computers, and the other classroom 131a (Fig. 3) with 10 computers. Computers are interconnected and connected to the Internet, with installed LanSchool (Teacher and Student Version) software, so that students can team-work on projects with monitoring and on-line help from teachers and associates. Also, it is planned that students also use the free internet platform Kahoot! which has proved to be very effective in acquiring new knowledge, because it stimulates interest of students and encourages them to think. Both classrooms have projectors, writing boards and smartboards, so they have all the necessary technical conditions for successful realization of the planned teaching activities. The third classroom to be used is the laboratory M1-4 (Fig. 4), equipped with modern models of 
real systems on which students can perform experiments in order to verify the designed control algorithms.

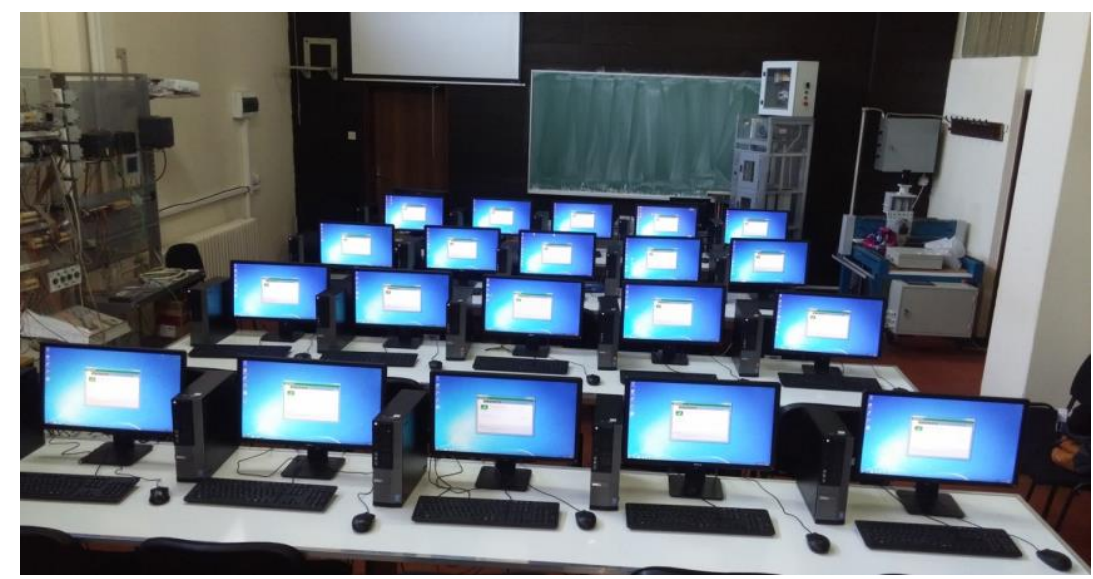

Fig. 1 Laboratory L24 - Working environment

\section{TEACHING METHODS}

An important part of the innovated courses will be practical individual and team projects where students will be able to develop teamwork competences, learn through experience, take initiative and plan and manage the project task - implementation of the intelligent control system, from the idea to the practical solution. During these activities, teachers will draw students' attention to errors, evaluate their work continuously, and form final grade that represents a sum of theoretical and practical knowledge as well as quality of teamwork within project teams. These projects should be tailored in such a manner that they can also help in the development of entrepreneurship competences [5] among the students in the sense of intensive participation in society, active job search and launching start-ups. Students will also have at their disposal the help of the recently established university's innovation and creativity center for the realization of their entrepreneurship ideas and innovations. The role of the Creativity Center of the University of Niš is to foster the creativity and innovation of young people in the academic population, and thus contribute to creating an environment in which they can realize their entrepreneurial and research potential.

The quality assurance of the teaching process of the group of innovated courses will include monitoring the dynamics of realization of the courses plans and programs, the professional attitude of teachers and associates towards work with students, regular monitoring and evaluation of students' work, as well as understanding and observing the requirements and needs of students. The innovated courses will be also evaluated by the partners from the business, especially the IT partner companies. The objectives of the evaluation will be to determine the level of satisfaction of the beneficiaries with the outcomes of the project, whether the project justified the initial expectations and contributed to the development of planned digital and entrepreneurial competences among students. 
Relevant feedback will enable teachers to correct possible mistakes and further improve the teaching cycle of the innovated courses for the next academic year.

\section{THE INNOVATION OF THE COURSES}

Three courses which will be innovated by the realization of project activities will be the topic of this section. The lecture topics of these courses and teaching methods which will be used for accomplishing syllabuses of the courses will be briefly presented.

\subsection{Artificial Intelligence Methods (Basic Academic Studies)}

The basic goal of the course is to teach students about the necessary theoretical knowledge of artificial intelligence and its popular methods (neural networks, fuzzy logic, genetic algorithms, hybrid systems) and to train students for a successful numerical realization of the mentioned intelligent systems, for their application and solving basic control problems. Exercises include detailed solutions of practical problems in numerical and grapho-analytical manners, which will enable students to learn in an easy and effective way how the intelligent system processes information, learns, minimizes errors and comes to the desired solutions.

During the course of Artificial Intelligence Methods students should also get trained for independent experimental work within the appropriate Matlab toolboxes (Neural Network Toolbox, Fuzzy Logic Toolbox, Global Optimization Toolbox) and be able to make the first professional steps in the field of artificial intelligence. The important task of all innovated courses is the development of digital competences among students [6]. The course is designed to enable the acquisition of an advanced level of digital competence through designing intelligent control logic, writing programs and implementing simple intelligent control systems in Matlab. In this way, students will be able to apply the acquired knowledge and to adjust the already written code to the variations of the problems they solve. Successful course mastering will also mean the ability of students to confidently solve a wide range of different types of problems using the artificial intelligence, to learn how to choose an intelligent system which is best for their problem and how to maximize its performance.

\subsection{Modern Control of Industrial Processes (Master Academic Studies)}

In order to respond to new technological innovations in the field of industrial production and other challenges of the fourth industrial revolution, the course Modern Control of Industrial Processes should be innovated in such a way that future Control Systems engineers will be trained in the basic concepts and applications of Industry 4.0 [7]. During the lectures, students shall receive a detailed training in the development of modern control methods and intelligent agents and acquire the capability of practical development of certain segments of the IIoT (Industrial Internet of Things) systems.

The emphasis will also be on mastering data processing and preprocessing techniques using machine learning as an important pre-requisite for the successful control of large systems. For this purpose, laboratory training of students for work in the Python programming language is planned, as well as writing machine learning programs for the 
needs of analysis and processing of large databases, data prediction and optimization of processes, realization of systems with artificial intelligence, and the use of designed systems for solving real-world problems. Project tasks will encompass the programming of the Arduino hardware platform as well as the design of simple IoT concepts [8] using the existing laboratory equipment, which will enable students to acquire an advanced level of digital competences. Students will have at their disposal equipment for industrial control given in Fig. 2 (Laboratory L24: Siemens, Omron and Schneider manufactured PLC and SCADA systems) and Fig. 3 (Laboratory 131a: Gunt and Feedback manufactured models for control of fluid flow, level, temperature, pressure and $\mathrm{Ph}$ value).

After attending the course, students will be competent to identify the problem, design and practically implement a system based on modern control and, ultimately, apply it to solve the real-world problem. Given the growing demand for artificial intelligence engineers, this course allows students to also develop entrepreneurial competences and become competitive in applying for jobs that in their description have the needs for the realization of intelligent systems.

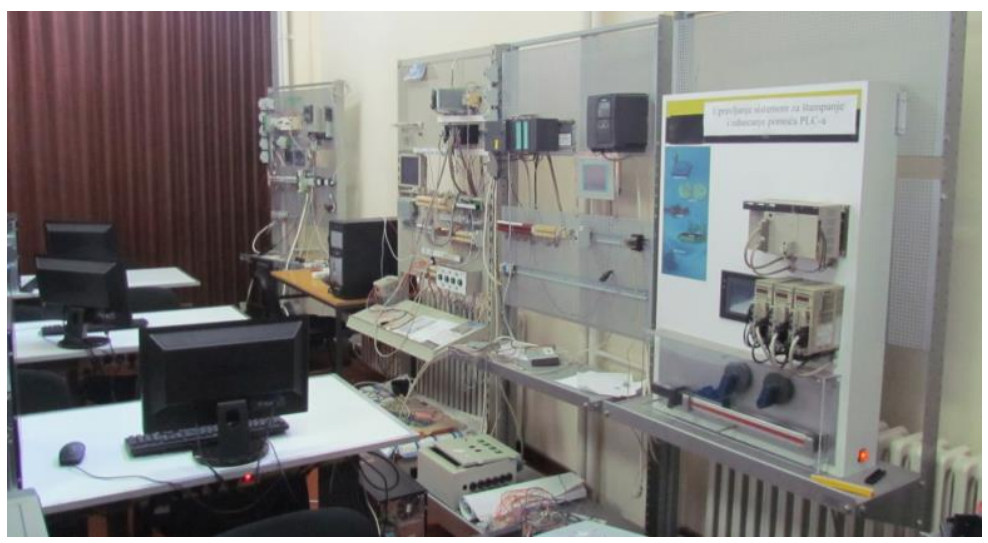

Fig. 2 Laboratory L24 - Industrial control devices

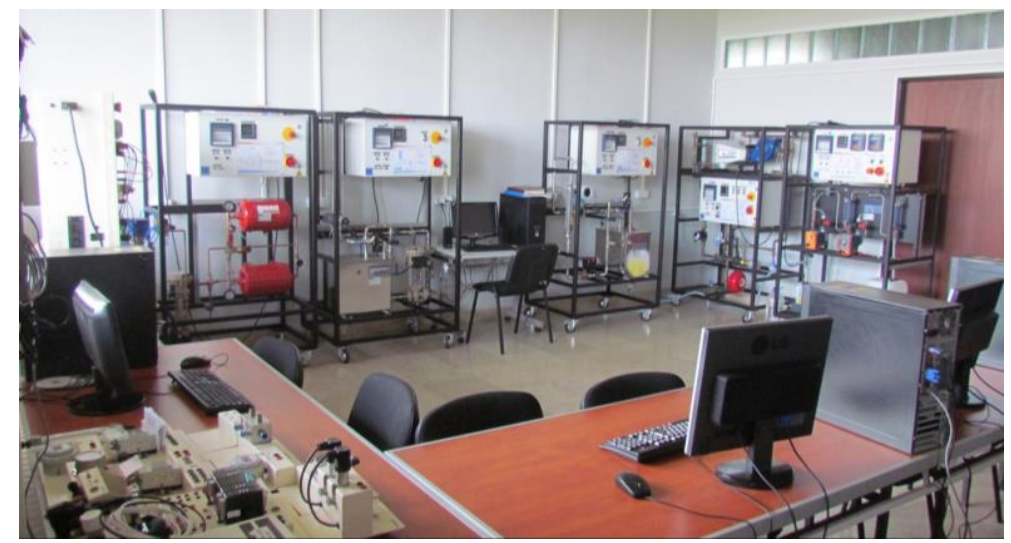

Fig. 3 Laboratory 131a 


\subsection{Intelligent Control (Doctoral Academic Studies)}

Intelligent Control, as a course of doctoral studies, represents the highest level of the practical work, design and realization of artificial intelligence systems and their use in intelligent control systems. The aim of the course is to train PhD students to independently develop complex intelligent control logics using the Python and $\mathrm{C}++$ programming languages and to get students engaged in scientific research aimed at mastering the latest technologies and methodologies for designing various systems with artificial intelligence. Lectures include intelligent control techniques, designing intelligent control logic, optimization of intelligent systems, designing and application of hybrid intelligent systems. Also, teaching content will include learning and practical implementation of the various intelligent control systems: ANFIS, recommender systems, machine learning systems, support vector machines, large scale machine learning systems.

Another objective of the course is an independent work of students on their final projects, training students for the use of online platforms and software of importance for scientific research (Kobson, Mendeley, Scopus, Academia, ResearchGate) and the writing of a scientific paper, based on experimental results, whose publication represents additional activity for passing the exam. After this course, $\mathrm{PhD}$ students should possess a highly specialized level of digital competences with the necessary theoretical and practical knowledge needed to solve complex problems of modern control and to successfully propose new ideas, technical solutions and innovations in the field of intelligent automation. PhD students will be able to try and validate all the designed intelligent control algorithms on the existing equipment in laboratory M1-4 displayed in Fig. 4 (modular servo system, ABS, twin rotor system, magnetic levitator, industrial crane, inverted pendulum, three tank hydraulic system).

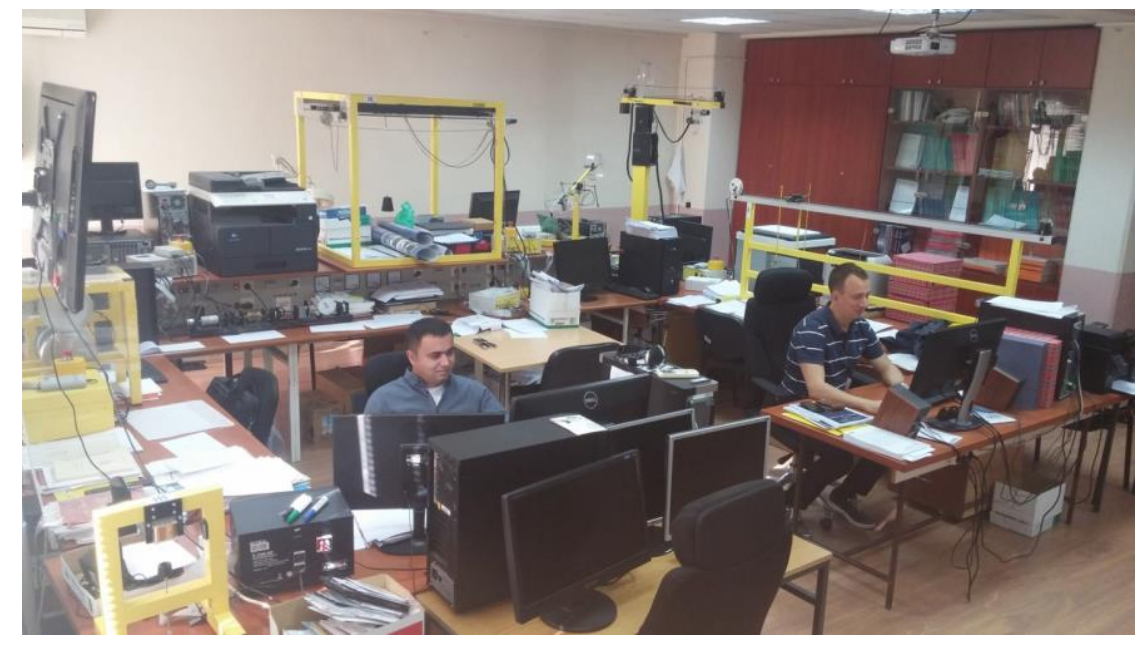

Fig. 4 Laboratory M1-4 


\section{CONCLUSION}

Ongoing changes in industrial production, caused by the development of information technologies and technological innovations, dictate continuous modernization in the education process. In order to respond to these demands, a group of teachers at the Department of Control Systems at the faculty of Electronic Engineering, University of Niš, developed a project "Implementation of Modern Intelligent Control Methods within the Control Systems Study Module", financed by Serbian Ministry of Education, Science and Technological Development in the scope of the project call "Development of Higher Education". The goal of the project is to modernize the curriculum for the study module of Control Systems through courses dealing with artificial intelligence and intelligent control: Artificial Intelligence Methods, Modern Control of Industrial Processes and Intelligent Control. The plan is not only to introduce new lecture topics and teaching methods, but also to strengthen the practical aspect of learning as well as to develop digital and entrepreneurship competences among the students.

Acknowledgement: This paper was realized as a part of the Projects TR 35005, III 43007, and III 44006 financed by the Ministry of Education, Science and Technological Development of the Republic of Serbia within the framework of technological development, integrated, and interdisciplinary research for the period 2011-2018.

\section{REFERENCES}

[1] S. Russell, P. Norvig, "Artificial Intelligence: A Modern Approach", Pearson, 2015.

[2] S. Perić, D. Antić, M. Milovanović, D. Mitić, M. Milojković, S. S. Nikolić, "Quasi-Sliding Mode Control with Orthogonal Endocrine Neural Network-Based Estimator Applied in Anti-lock Braking System", IEEE/ASME Transactions on Mechatronics, vol. 21, no. 2, pp. 754-764, IEEE, 2016. [Online]. Available: http://dx.doi.org/10.1109/TMECH.2015.2492682.

[3] M. Milovanović, D. Antić, M. Milojković, S. S. Nikolić, S. Perić, M. Spasić, "Adaptive PID Control Based on Orthogonal Endocrine Neural Networks", Neural Networks, vol. 84, pp. 80-90, Elsevier Ltd, 2016. [Online]. Available: https://doi.org/10.1016/j.neunet.2016.08.012.

[4] M. Milovanović, D. Antić, M. Milojković, S. S. Nikolić, M. Spasić, S. Perić, "Time Series Forecasting with Orthogonal Endocrine Neural Network Based on Postsynaptic Potentials", Journal of Dynamic

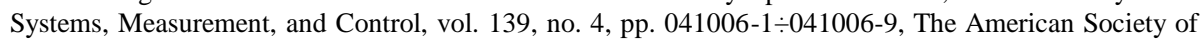
Mechanical Engineers - ASME, 2017. [Online]. Available: https://doi: 10.1115/1.4035090.

[5] M. Bacigalupo, P. Kampylis, Y. Punie, G. Van den Brande, "EntreComp: The Entrepreneurship Competence Framework", Publications Office of the European Union, 2016.

[6] S. Carretero, R. Vuorikari, Y. Punie, "The Digital Competence Framework for Citizens", Publications Office of the European Union, 2017.

[7] K. Schwab, "The Fourth Industrial Revolution", Currency, 2017.

[8] A. Bahga, V. Madisetti, "Internet of Things (A Hands-on-Approach)", VPT, 2014. 